\title{
Effect of an Emotion Regulation Training Intervention on Social Functioning of Patients with Psychiatric Disorders
}

\author{
AnghamElsaid Tawfik ${ }^{1}$,Souzan Abd El-Menem Abd El-Ghafar Harfush ${ }^{2}$, Ehab \\ Ramadan $^{3}$, EssmatM. Gemeay ${ }^{4}$
}

\author{
${ }^{1}$ Assistant lecturer of Psychiatric \&Mental Health Nursing, Faculty of Nursing, Tanta \\ University. \\ ${ }^{2}$ Lecturer of Psychiatric \&Mental Health Nursing, Faculty of Nursing, Tanta University. \\ ${ }^{3}$ Professor of Neuropsychiatry, Faculty of Medicine, Tanta University. \\ ${ }^{4}$ Professor of Psychiatric \&Mental Health Nursing, Faculty of Nursing, Tanta University.
}

\begin{abstract}
Emotion dysregulation and social dysfunction are core characteristic of many psychiatric disorders such as schizophrenia and mood disorders. Medication-based treatment for patients with psychiatric disorders may alleviate acute clinical symptoms; however, it is limited in terms of its ability to improve social and emotional functions. There is evidence highlighting the central role of emotion regulation deficits in determining social functioning in individuals with psychiatric disorders. Therefore, emotion-related training intervention is needed to enhance patient's awareness and expression of emotions and for successful social functioning.Aim: the aimof this study was to evaluate the effect of an emotion regulation training intervention on social functioning of patients with psychiatric disorders.Setting: The present study was conducted at psychiatric inpatient department of TantaUniversity Hospital that is affiliated to Tanta University. Subjects: 60 patients with psychiatric disorders divided randomly into experimental and control group (30 patients in eachgroup).Tools:Difficulties in Emotion Regulation Scale and Social Functioning Scale were used to collect the study data. Design:A randomized controlled trial was conducted. The intervention was conducted through 9 training sessions, each session lasting from (60-90) minutes; 3 times per week for a period of 4 weeks. Results: there was a statistically significant improvement in social functioning and emotion regulation in the experimental groupthan the control group after the implementation of the intervention. Also, a statistically significant negative correlation was found between emotion regulation difficulties and social functioning.Conclusions :Emotion regulation training intervention has a salient effect on reducing emotion regulation difficulties and improving social functioning in patients with psychiatric disorders. Recommendations: this non-pharmacological evidence-based-nursing practice should be incorporated in the psychiatric hospital protocol for cumulative and consistent effects
\end{abstract}

Keywords: Social functioning, emotion regulation, psychiatric disorders, emotion regulation training intervention. 


\section{Introduction}

Emotion is generally viewed as a relatively brief form of affect that arises when external or internal stimuli signal to the individual that something important may be at stake ${ }^{(1)}$.Psychologists identified several important functions of emotion in our daily lives; it serves as a guide for human behavior; helps to prepare behavioral reactions quickly and in an automatic fashion and shapes future behavior, makes life interesting, and helps to interact more effectively with others ${ }^{(2)}$. Emotional responses are typically considered to be comprised of multiple components including cognitive, behavioralor expressive, physiological, and subjective components ${ }^{(3)}$.

Emotion are not passively experienced and expressed but are often regulated and this is called emotional regulation ${ }^{(4)}$. Emotional regulation is defined as the intrinsic and extrinsic processes responsible for monitoring, evaluating, and modifying emotional reactions, especially their intensive and temporal features to accomplish one's goals ${ }^{(5)}$. By regulating emotion individuals can determine which emotions they have, when they have, and how they experience and express these emotions $^{(2)}$. Emotion regulation plays an important role in shaping not only momentary emotion experience and behavior, but also broader and more enduring features of psychological functioning such assatisfying hedonic needs that aimed at producing pleasure and reducing pain, facilitatingof specific goals and tasks,and optimization of social functioning ${ }^{(6,7)}$.Emotion impairment problems are cardinal feature of many psychiatric disorders such as schizophrenia, major depressive disorders, bipolar disorders, and personality disorders (8). Patients with schizophrenia display a facial emotional bias and perception impairment. Many disorders such as depression, mania, dementia, and autism have demonstrated these deficiencies ${ }^{(9)}$.They can't recognize negative emotions such as anger or worries and view them as neutral expression ${ }^{(10)}$. These defects can be observed in all stages of schizophrenia including the prodromal stage ${ }^{(11)}$.It is also found in patients with bipolar disorder and still present even after remission $^{(12)}$. Moreover, they have restriction in the range of emotional experience and expression in response to emotional stimuli. The disjunction between the experience and the expression of emotion may reflect disturbances in emotion regulation which interfere with the 
achievement of these important emotionrelated functions and evoke negative responses from others. Consequently it leads to difficulties in engaging or maintaining social functions ${ }^{(9,13)}$.Emotion regulation refers to the set of processes whereby people seek to monitor, appraise, and redirect the spontaneous flow of their emotions in accordance with their needs, goals and related demands ${ }^{(5)}$. By regulating emotion individuals can determine which emotions they have, when they have, and how they experience and express these emotions ${ }^{(4)}$. It is a cornerstone of normal development and optimal psychological functioning such as shaping momentary emotion experience and behavior, satisfying hedonic needs that producing pleasure and reducing pain, facilitatingspecific goals and tasks, and optimization of social functioning ${ }^{(6,14)}$.

Emotions are essential for social functioning as they provide information about the significance of current social situations, and also give clues for the actions to be taken in such situations. Social functioning includes everything needed to successfully live such as independent living skills (cooking, cleaning, hygiene, etc.), engaging in positive relationships with family, friends, and significant others, as well as performance at school and work ${ }^{(15)}$.
Patients with psychiatric disorders experience problems in social functioning; these problems are significantly resulting from emotion awareness and regulation difficulties. Medication-based treatment for patients with psychiatric disorders may alleviate acute clinical symptoms; however, it is limited in terms of its ability to improve social and emotional functions. Therefore it is necessary to implement an intervention for managing emotion in order to improve their social functioning ${ }^{(16)}$.

Emotion regulation training intervention is considered an evidence-based nursing care focused on emotional problems of patients with psychiatric disorders. Through it the patients will be aware of their emotions, label and express it in socially appropriate manner, become emotionally regulated, and have better social functioning ${ }^{(17)}$.

\section{Aim of the study}

To evaluate the effect of an emotion regulation training intervention on social functioning ofpatients with psychiatric disorders.

\section{Subjects and method}

\section{Study Design}

A randomized controlled trial.

SettingThe present study was conducted at Psychiatricin patient department of TantaUniversity Hospitalwith a capacity of 31 beds divided into two wards for men 
(17 beds) and two wards for women (14 beds).

\section{Subjects}

A purposive sample of 60 patients with psychiatric disordersrandomly allocated into experimental and control group using concealed sealed envelops. Once the patient has consented to enter the trial an envelope is opened to randomly assign patients to (experimental group 30 patients) or (control group 30 patients). The sample size estimated using EPi-Info created by World Health Organization and Center for Disease Control and Prevention, Atlanta, Georgia, USA version 2002 ;95\% confidence limit, $80 \%$ power of the study, Ratio between treatment and control group 1:1, and Expected level of social functioning $30 \%$ before intervention that will be improved to $70 \%$ after intervention. Based on these criteria the sample size was $\mathrm{N}>25$ (for each group).

\section{Inclusion criteria}

Age at least 18 years, both sexes, able to communicate relevantly, agree to participate in the study.

ExclusionAcute stage of illness and any evidence of organic brain disease, mental retardation, and or substance use disorders.

\section{Tools of data collection}

\section{Difficulties in Emotion Regulation Scale}

It is developed by Gratz \& Roemer $(2004)^{(18)}$ to measure the difficulties with emotion regulation. Itconsisted of 36 items;all wererated on a five Likert scale ranging from (1) almost never to (5) almost always, excepteleven itemsrepresent negative responses which must be reversed score.Higher score reflectinggreater problems with emotion regulation. Cronboch's alpha was 0.93

\section{Social Functioning Scale}

It is developed by Birchwood $(1991)^{(19)}$. It is composed of 77 items divided into seven subscales whichmeasure thepatient's performance and abilities in the following:Social engagement/withdrawal(5items).Interperso nal communication(4items), Independence performance (13 items).Independence competence (13 items), Recreation (15 items). Prosocial activities items),occupation/employment (5 items) Four items were rated as Yes or No, one item records the time of getting up, one item was rated on a three-point Likert scale, two items wererated on a five-point Likert scale, and the rest of items were rated on a four-point Likert scale ranging from $0=$ never to $3=$ often. Higher score indicating better social functioning. Cronboch's alpha was 0.80 .

\section{Sociodemographic and clinical data}

A structured interview schedule used to elicit data aboutage, sex, occupation, level of education, marital status, duration of 
illness, insight, mode of admission and medical diagnosis.

\section{Method}

An official permission was addressed from the dean of the faculty of nursing Tanta University to the manager of psychiatric department to gain approval and cooperation for data collection.

\section{Ethical consideration}

- Study procedure was revised and approved by the ethical Committee of the Faculty of Medicine, Tanta University (approval code 32502/08/18)and Faculty of nursing, Tanta University.

- Approved in Iranian Registry of Clinical Trial (registration reference is IRCT20200402046920N1).

- Written informed consent was taken from the patient and Privacy was protected and answers kept confidential.

- The study subjects had the right to withdrawn from this study at any time without any negative impact on services they were currently receiving or were received in the future.

- The study would not produce any harm or pain to the patients.

Actual study: the actual study consisted of four phases:

\section{Preparation phase}

The measures were translated by the researcher into Arabic language then reviewed for translation accuracy and tested for content validity by three experts in the psychiatric nursing and medicine field and back translated by other two experts. A pilot study carried out on 6 patients to test the applicability and clarity of the study measures. No modifications were done. These patients were excluded from the total study subjects. The study measures were applied on both groups using the interview method on an individual basis as a baseline.

\section{Planning phase}

Emotion regulation training intervention was developed by the researcher based on reviewing the related literature ${ }^{(17,20)}$. Its content was prepared by the researcher under the direction of the supervisors including; pictures, colored papers, different colors, some vignettes containing different emotions, and cartoon films.

The experimental group was divided into subgroups. Each subgroup ranged between 4to 6 patients. The emotionregulation training program was conducted through9 trainingsessions, each lasting from (60-90) minutes; 3 times per week for a period of 4 weeks started from February to July 2019.

\section{Implementation phase}

The emotion regulation training program was conducted by covering the following four stages with a series of 9 training exercises. 
Stage (one) Emotional perception training: The aim of this stage is to help the patient to identify and understand emotions. It comprisedfour exercises that conducted into twosessions (two exercises in each). Session (1): The first and second exercise intended to help the subjects to recognize emotion

- Understanding emotional words: expressing emotion by using emotion word cards (happy)

- Learning emotional words: matching emotional word cards and emotional face cards.

Session (2): The third and fourth exercises intended to help the subjects to identify emotion

- Finding emotional words:choosing emotional word cards from emotional face cards that represent different emotions.

- Identifying emotion by context:choose emotional word cards from a short film cartoon that represent certain emotions.

Stage (two)Emotion expression training: The aim of this stage was to help the patient to express emotions. This stage comprisedfour exercises that wasconduct into three sessions.

Session (3): The fifth and sixth exercise intended to help the subjects to express emotions
- Making facial expression: the patients expressed emotions by emotional face cards.

- Facial expression relay: Identifying one's facial expression and passing it to the next person. This procedure was applied on all emotional face cards where each patient in the group will draw different facial expressions

Session (4): The seventhexercise wasperformed to help the patients to express emotion by using image.

Storytelling and watching a film and expressing emotion. The researcher asked the patients to write or draw their feelings after emotional storytelling and watching a film cartoon.

Session (5): The eighth exercise in this session wasto help the patients to express emotion byusing sentence.

Expressing emotionusing written instructions: Each patient by turnwas picking a card with a written instruction of certain emotional expression in a group.

Stage (three) Emotion application training.The aim of this stage was to help the patient to share their feelings, understand complex emotionand emotional inference. This stage comprisedthree exercises that conducted into two sessions. 
Session (6): The nineth exercise was appliedto help the patients to share their feelings.

Emotional mask: making emotional mask by drawing one's feeling on a mask then wearing each emotional mask and expressing their feelings.

Session(7): The tenth and eleventh exercises were used to help the patients to understand complex emotion and emotion inference

Making facial expressions by context: expressing feelings using written emotional sentences.

Exercising emotional inference: making up a story with emotional sentence cards.

Stage( four) Emotionalcontrol training.

Sessions $(8,9)$ : The aim of this stage is to help the patient to develop self -awareness and cope with negative emotions.

The researcher used the following learning strategies: modeling, role play/ behavioral rehearsal, getting participant's feedback (e.g. providing corrective feedback) and positive reinforcement.

\section{Evaluation phase}

At the end of the intervention immediately and after 3 months, posttest was done using the study measures for both the experimental and control groups

\section{Statistical analysis}

The Statistical Package for Social Sciences (SPSS version 20) was utilized.
Kolmogorov-Smirnov test was used to evaluate the normality of the data. For numerical values the range, mean, and standard deviations were calculated. The differences between two mean values were used using student's $t$ testwhen the variable presented normal distribution and MannWhitney - test was used when the normal distribution of data was not guaranteed.

Differences of mean values between more than two groups were tested by analysis of variance.For categorical variable; the number and percentage were calculated and differences between subcategories were tested by Chi square and Fisher Exact test. Correlation between variables was evaluated using Pearson's and spearman's correlation coefficient r. Statistical analyses were consideredsignificant at $p$ $<.05$.

\section{Results}

Table(1) illustrates the sociodemographic \&clinical characteristics of the studied groups. No statistically significant difference was found in relation to all socio-demographic \&clinical characteristics. The absence of any statistically significant difference between the studied groups can reflect that both groups were almost matched .

Figure (1) shows the distribution of thestudied patients by their emotion regulation difficulties throughout the phase 
of intervention. At pre intervention phase there was no statistically significant difference between the experimental and control group $\left(\mathrm{X}^{2}=1.052, \mathrm{P}=0.590\right)$. At post intervention phase the percentage of the studied patients who had high emotion regulation difficulties dropped to $23.3 \%$ for the experimental group compared to $53.3 \%$ for the control group. Likewise, $50 \%$ of patients in the experimental group had low emotion regulation difficulties compared to $20 \%$ in the control group. With statistically significant difference between them $\left(\mathrm{X}^{2}=7.379, \mathrm{P}=0.025\right)$. At the follow up phase $20 \%$ of the patients in the experimental group had a high emotion regulation difficulties compared to $50 \%$ in the control one, while $36.7 \%$ of patients in the experimental group had low emotion regulation difficulties compared to $16.7 \%$ in the control group. With a statistically significant difference between them $\left(X^{2}=6.501, p=0.039\right)$.

Figure (2 )shows the distribution of the studied patients by their social functioning throughout the phases of intervention. At pre intervention phase there was no statistically significant difference between the experimental and control group $\left(\mathrm{F}^{\mathrm{ET}}=\right.$ 0.218, $\mathrm{P}=0.896$ ). At post intervention phase $23.3 \%$ of the patients in the experimental group had good social functioning compared to only $3.3 \%$ in the control group. Whereas $16.7 \%$ of patients in the experimental group had poor social functioning compared to $76.7 \%$ in the control one with a statistically significant difference between them $\left(\mathrm{F}^{\mathrm{ET}}=22.073\right.$, $\mathrm{P}=0.001$ ). At the follow up phase $16.7 \%$ of patients in the experimental group had a good social functioning compared to $3.3 \%$ in the control one, while $43.3 \%$ of patients in the experimental group had poor social functioning compared to $83.3 \%$ in the control group with a statistically significant difference between them $\left(\mathrm{F}^{\mathrm{ET}}=6.491 \mathrm{p}=\right.$ 0.030).

Table (2) Comparison between the experimental and control group regarding their emotion regulation difficulties throughout the phases of intervention .It can be noticed that the mean score of total emotion regulation difficulties of the experimental group decreased from $135.5 \pm 42.8$ pre intervention to $89.8 \pm 44.16$ post intervention with a statistically significant difference P1:0.001, and also decreased to108.8 \pm 32.6 at follow up with a statistically significant difference P2:0.020. Whereas the mean score increased from $89.8 \pm 44.16$ post intervention to $108.8 \pm 32.6$ at follow up with a statistically significant difference between them P3:0.046. This means there was a statistical improvement in the emotion regulation immediately after implementation of the intervention 
and this improvement declined at follow up but still significant than pre intervention.

Table (3) represents Comparison between the experimental and control group regarding their social functioning throughout the phases of intervention. It can be noticed that the mean score of total social functioning of the experimental group increased from $74.40 \pm 37.24$ pre intervention to $125.33 \pm 30.91$ post intervention with a statistically significant difference P1:0.001, and also increased to $97.41 \pm 38.42$ at follow up with a statistically significant difference P2:0.037. Whereas the mean score decreased from $125.33 \pm 30.91$ post intervention to97.41 \pm 38.42 at follow up with a statistically significant difference between them P3:0.001. This means there was a statistical improvement in the social functioning immediately after implementation of the intervention and this improvement declined at follow up but still significant than pre intervention.

Table (4) describes the correlation between emotion regulation difficulties and social functioning, there was a statistically significant negative correlation between social engagement, interpersonal communication,independence, performanc e, independence competence, prosocial activities, total social functioning and emotion regulation difficulties $(r=-0.493$ $\mathrm{P}=0.006, \mathrm{r}=-0.743 \mathrm{P}=0.001, \mathrm{r}=-0.570 \mathrm{P}=$ $0.001, r=-0.503 \mathrm{P}=0.005, \mathrm{r}=-510$ $\mathrm{P}=0.004 \quad, \quad \mathrm{r}=-0.738 \quad \mathrm{P}=0.001$ respectively).This means decreasing difficulties in emotion regulation leading to improvement in social functioning. While there was no statistically significant correlation between recreational activities and employment subscale and emotion regulation difficulties $(r=-0.326 \mathrm{p}=0.079$, $\mathrm{r}=-0.252 \mathrm{p}=0.179)$ respectively 
Table (1) Distribution of the studied patients by their socio-demographic \&clinical characteristics

\begin{tabular}{|c|c|c|c|c|c|}
\hline \multirow{2}{*}{$\begin{array}{c}\text { Sociodemographic \& clinical } \\
\text { characteristics }\end{array}$} & \multicolumn{2}{|c|}{ Experimental group } & \multicolumn{2}{|c|}{ Control group } & \multirow{2}{*}{$\begin{array}{c}\text { Test of } \\
\text { significance }\end{array}$} \\
\hline & $\mathbf{N}$ & $\%$ & $\mathbf{N}$ & $\%$ & \\
\hline $\begin{array}{l}\text { Age } \\
<20 \\
20-29 \\
30-39 \\
40-49 \\
\geq 50\end{array}$ & $\begin{array}{l}0 \\
11 \\
13 \\
5 \\
1\end{array}$ & $\begin{array}{l}0 \\
36.7 \\
43.3 \\
16.7 \\
3.3\end{array}$ & $\begin{array}{l}1 \\
11 \\
10 \\
4 \\
4\end{array}$ & $\begin{array}{l}33.3 \\
36.7 \\
33.3 \\
13.3 \\
13.3\end{array}$ & $\begin{array}{l}\mathrm{F}^{\mathrm{ET}}=3.302 \\
\mathrm{P}=0.509\end{array}$ \\
\hline $\begin{array}{l}\text { Range } \\
\text { Mean } \pm \text { S.D }\end{array}$ & \multicolumn{2}{|c|}{$\begin{array}{l}20-60 \\
32.93 \pm 9.07\end{array}$} & \multicolumn{2}{|c|}{$\begin{array}{l}19-58 \\
33.87 \pm 10.44\end{array}$} & $\begin{array}{l}\mathrm{T}=0.137 \\
\mathrm{P}=0.713\end{array}$ \\
\hline $\begin{array}{l}\text { Sex } \\
\text { Male } \\
\text { Female }\end{array}$ & $\begin{array}{l}16 \\
14\end{array}$ & $\begin{array}{l}53.3 \\
46.7\end{array}$ & $\begin{array}{l}15 \\
15\end{array}$ & $\begin{array}{l}50 \\
50\end{array}$ & $\begin{array}{l}X^{2}=0.067 \\
P=0.796\end{array}$ \\
\hline $\begin{array}{l}\text { Occupation } \\
\text { Not worked } \\
\text { Worked }\end{array}$ & $\begin{array}{l}20 \\
10\end{array}$ & $\begin{array}{l}66.7 \\
33.3\end{array}$ & $\begin{array}{l}21 \\
9\end{array}$ & $\begin{array}{l}70 \\
30\end{array}$ & $\begin{array}{l}X^{2}=0.077 \\
P=0.781\end{array}$ \\
\hline $\begin{array}{l}\text { Education } \\
\text { Illiterate/ read and write } \\
\text { Primary } \\
\text { Preparatory } \\
\text { Secondary } \\
\text { University }\end{array}$ & $\begin{array}{l}2 \\
2 \\
5 \\
12 \\
9\end{array}$ & $\begin{array}{l}6.7 \\
6.7 \\
16.7 \\
40 \\
30\end{array}$ & $\begin{array}{l}1 \\
3 \\
3 \\
13 \\
10\end{array}$ & $\begin{array}{l}33.3 \\
10 \\
10 \\
43.3 \\
33.3\end{array}$ & $\begin{array}{l}\mathrm{F}^{\mathrm{ET}}=1.128 \\
\mathrm{P}=0.890\end{array}$ \\
\hline $\begin{array}{l}\text { Marital } \\
\text { Single } \\
\text { Married } \\
\text { Divorced/ separated } \\
\text { Widowed }\end{array}$ & $\begin{array}{l}14 \\
11 \\
5 \\
0\end{array}$ & $\begin{array}{l}46.7 \\
36.7 \\
16.7 \\
0\end{array}$ & $\begin{array}{l}14 \\
11 \\
4 \\
1\end{array}$ & $\begin{array}{l}46.7 \\
36.7 \\
13.3 \\
3.3\end{array}$ & $\begin{array}{l}\mathrm{F}^{\mathrm{ET}}=1.111 \\
\mathrm{P}=0.774\end{array}$ \\
\hline $\begin{array}{l}\text { Duration of illness } \\
<5 \\
5- \\
10- \\
\geq 15\end{array}$ & $\begin{array}{l}14 \\
11 \\
5 \\
0\end{array}$ & $\begin{array}{l}46.7 \\
36.7 \\
16.7 \\
0\end{array}$ & $\begin{array}{l}14 \\
11 \\
4 \\
1\end{array}$ & $\begin{array}{l}46.7 \\
36.7 \\
13.3 \\
3.3\end{array}$ & $\begin{array}{l}\mathrm{F}^{\mathrm{ET}}=1.111 \\
\mathrm{P}=0.774\end{array}$ \\
\hline
\end{tabular}




\begin{tabular}{|c|c|c|c|c|c|}
\hline $\begin{array}{l}\text { Range } \\
\text { Mean } \pm \text { SD }\end{array}$ & \multicolumn{2}{|c|}{$\begin{array}{l}1-26 \\
7.42 \pm 6.52\end{array}$} & \multicolumn{2}{|c|}{$\begin{array}{l}1-24 \\
7.20 \pm 5.94\end{array}$} & $\begin{array}{l}\mathrm{Z}_{\mathrm{MW}}=0.018 \\
\mathrm{P}=0.893\end{array}$ \\
\hline $\begin{array}{l}\text { Yes } \\
\text { No }\end{array}$ & $\begin{array}{l}4 \\
26\end{array}$ & $\begin{array}{l}13.3 \\
86.7\end{array}$ & $\begin{array}{l}6 \\
24\end{array}$ & $\begin{array}{l}20 \\
80\end{array}$ & $\begin{array}{l}\mathrm{F}^{\mathrm{ET}}=0.480 \\
\mathrm{P}=0.488\end{array}$ \\
\hline $\begin{array}{l}\text { Mode of admission } \\
\text { Voluntary } \\
\text { Involuntary }\end{array}$ & $\begin{array}{l}5 \\
25\end{array}$ & $\begin{array}{l}16.7 \\
83.3\end{array}$ & $\begin{array}{l}7 \\
32\end{array}$ & $\begin{array}{l}23.3 \\
76.7\end{array}$ & $\begin{array}{l}X^{2}=0.408 \\
P=0.519\end{array}$ \\
\hline $\begin{array}{l}\text { Diagnosis } \\
\text { Schizophrenia } \\
\text { Depression } \\
\text { Bipolar }\end{array}$ & $\begin{array}{l}17 \\
5 \\
8\end{array}$ & $\begin{array}{l}56.7 \\
16.7 \\
26.7\end{array}$ & $\begin{array}{l}15 \\
7 \\
8\end{array}$ & $\begin{array}{l}50 \\
23.3 \\
26.7\end{array}$ & $\begin{array}{l}X^{2}=0.462 \\
P=0.795\end{array}$ \\
\hline
\end{tabular}

T: student t- test $\quad \mathrm{X}^{2}$ : Chi-square test $\quad \mathrm{F}^{\mathrm{ET}}$ : Fisher's exact test $\mathrm{Z}_{\mathrm{Mw}}$ : Mann-Whitney test

*Significant at level $\mathrm{P} \leq 0.05$

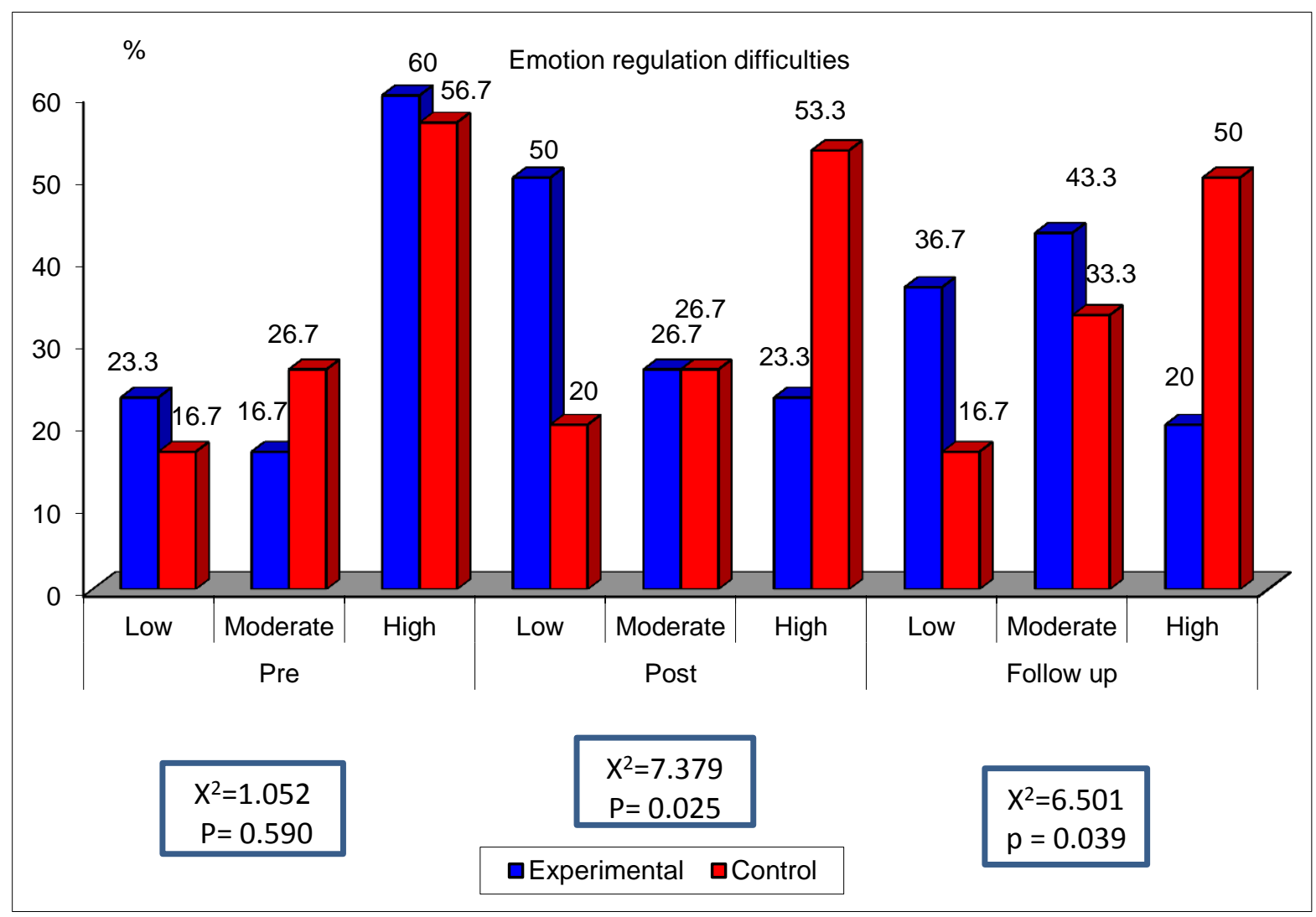

Figure (1) Distribution of the studied patients by their emotion regulation difficulties throughout the phases of intervention 


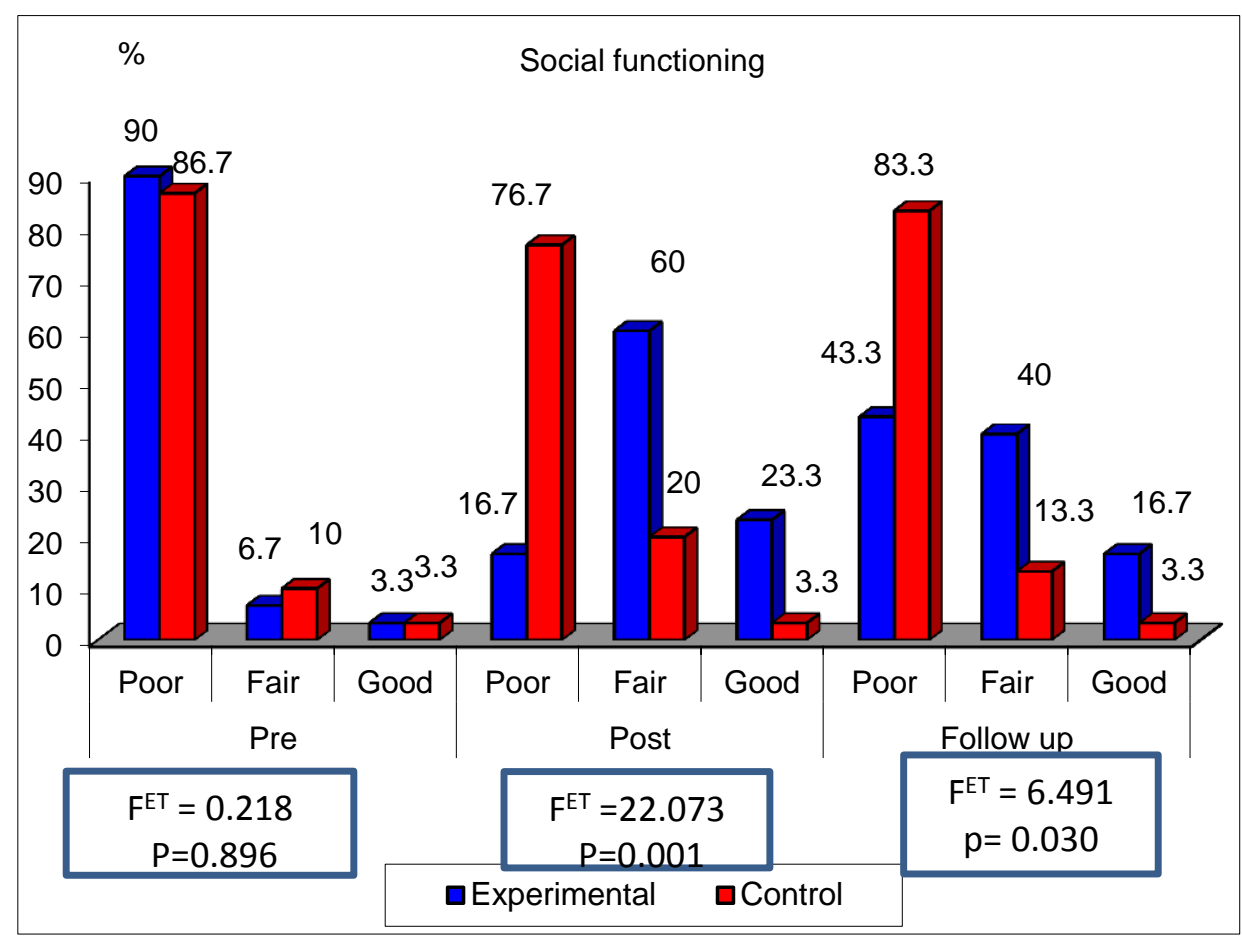

Figure (2) Distribution of the studied patients by their social functioning throughout thephases of intervention

Table (2 ) Comparison between the experimental and control group regarding their emotion regulation difficulties throughout the phases of intervention.

\begin{tabular}{|c|c|c|c|}
\hline Emotion regulation difficulties & Experimentalgroup & Control group & Test of significance \\
\hline $\begin{array}{l}\text { Pre intervention } \\
\text { Range } \\
\text { Mean } \pm \text { SD }\end{array}$ & $\begin{array}{l}52-175 \\
135.5 \pm 42.8\end{array}$ & $\begin{array}{l}59-174 \\
135.8 \pm 37.9\end{array}$ & $\begin{array}{l}\mathrm{T}=0.028 \\
\mathrm{P}=0.980\end{array}$ \\
\hline $\begin{array}{l}\text { Post intervention } \\
\text { Range } \\
\text { Mean } \pm \text { SD }\end{array}$ & $\begin{array}{l}41-173 \\
89.8 \pm 44.16\end{array}$ & $\begin{array}{l}65-174 \\
133.1 \pm 38.6\end{array}$ & $\begin{array}{l}\mathrm{T}=4.042 \\
\mathrm{P}=0.001 *\end{array}$ \\
\hline $\begin{array}{l}\text { Follow up } \\
\text { Range } \\
\text { Mean } \pm \text { SD } \\
\text { Test of significance }\end{array}$ & $\begin{array}{l}56-174 \\
108.8 \pm 32.6 \\
\text { F } P 1: 0.001^{*} \\
{ }^{\text {F }} \text { P2: } 0.020^{*} \\
\text { F P3: } 0.046^{*}\end{array}$ & $\begin{array}{l}59-174 \\
128.0 \pm 35.9 \\
\text { F } \text { P1: } 0.786 \\
\text { F } \text { P2: } 0.424 \\
\text { F } \text { P3: } 0.597\end{array}$ & $\begin{array}{l}\mathrm{T}=2.169 \\
\mathrm{P}=0.039 *\end{array}$ \\
\hline
\end{tabular}

T: student t- test

F: ANOVA test

*Significant at level $\mathrm{P} \leq 0.05$

P1: comparison between pre and post intervention. P2: comparison between pre intervention and follow up. P3: comparison between post intervention and follow up. 
Table (3) Comparison between the experimental and control group regarding their social functioning throughout the phases of intervention

\begin{tabular}{|c|c|c|c|}
\hline Social functioning & Experimental group & Control group & Test of significance \\
\hline $\begin{array}{l}\text { Pre intervention } \\
\text { Range } \\
\text { Mean } \pm \text { SD }\end{array}$ & $\begin{array}{l}7-193 \\
74.40 \pm 37.24\end{array}$ & $\begin{array}{l}23-169 \\
71.60 \pm 33.75\end{array}$ & $\begin{array}{l}\text { ZMW }=0.312 \\
P=0.761\end{array}$ \\
\hline $\begin{array}{l}\text { Post intervention } \\
\text { Range } \\
\text { Mean } \pm \text { SD }\end{array}$ & $\begin{array}{l}74-183 \\
125.33 \pm 30.91\end{array}$ & $\begin{array}{l}30-172 \\
81.03 \pm 34.10\end{array}$ & $\begin{array}{l}\mathrm{ZMW}=5.273 \\
\mathrm{P}=0.001 *\end{array}$ \\
\hline $\begin{array}{l}\text { Follow up } \\
\text { Range } \\
\text { Mean } \pm \mathrm{SD} \\
\text { Test of significance }\end{array}$ & $\begin{array}{l}27-196 \\
97.41 \pm 38.42 \\
\text { F P1: } 0.001 * \\
\text { F P2: } 0.037 * \\
\text { F P3: } 0.001 *\end{array}$ & $\begin{array}{l}32-167 \\
76.67 \pm 33.40 \\
\text { F } \mathrm{P} 1: 0.282 \\
\text { F } \mathrm{P} 2: 0.562 \\
{ }^{\mathrm{F}} \mathrm{P} 3: 0.618\end{array}$ & $\begin{array}{l}\mathrm{ZMW}=2.233 \\
\mathrm{P}=0.030^{*}\end{array}$ \\
\hline
\end{tabular}

F: ANOVA testZ $Z_{\mathrm{Mw}}$ : Mann-Whitney test

*Significant at level $\mathrm{P} \leq 0.05$

P1:comparison between pre and post intervention. P2: comparison between pre intervention and follow up.

P3: comparison between post intervention and follow up.

Table (4) Correlation between emotion regulation difficulties and social functioning of the experimental group post intervention $(n=30)$

\begin{tabular}{|l|c|c|}
\hline Social functioning & Emotion regulation difficulties \\
\cline { 2 - 3 } & $\mathbf{r}$ & $\mathbf{P}$ \\
\hline Social engagement & -0.493 & $0.006^{*}$ \\
\hline Interpersonal communication & -0.743 & $0.001^{*}$ \\
\hline Independence (performance) & -0.570 & $0.001^{*}$ \\
\hline Independence (Competence) & -0.503 & $0.005^{*}$ \\
\hline Recreational activities & -0.326 & 0.079 \\
\hline Prosocial activities & -510 & $0.004^{*}$ \\
\hline Employment & -0.252 & 0.179 \\
\hline Social functioning total & -0.738 & $0.001^{*}$ \\
\hline
\end{tabular}

*Significant at level $\mathrm{P} \leq 0.05$

$\mathrm{r}=$ spearman's rho coefficient 


\section{Discussion}

Patients with psychiatric disorders have many emotional problems because they can't express their emotions although they have feelings. Patients are appeared apathetic because their emotional expressions do not work effectively while the biological responses are preserved. Emotional deficits affect different processes such as face emotional expression as well as the domains of perception and recognition ${ }^{(21-23)}$. Clinical researchers stated that individuals who have serious psychiatric disorders have problems with emotion regulation that affects their social functioning in consequence (24). Therefore, improving patients' emotion regulation skills has been suggested as a promising target in the treatment of various psychiatric disorders $^{(25)}$.

Results of the present study showed that patients who received emotion regulation training intervention were significantly improved in the total emotion regulation than control group immediately after implementing theintervention. Although this improvement declined after three months but still significantly better than pre intervention which means it needs to be provided continually for cumulative and consistent effect. This finding may be attributed to the skills acquired during the implementation of emotion regulation training intervention itself, as the intervention incorporates a wide variety of exercises that all aimed at providing patients with the opportunities to learn and apply several emotional skills such as expressing emotions by mean of facial expression ,verbal language, and behaviors. These exercises were applied by materials more attractive and interesting for the patients which enhance learning and acquisition of skills such as cartoon films \& telling stories containing different emotions, as well as emotions cards.

Additionally , a variety of behavioral techniques were used in the current emotion regulation training intervention, the demonstration of the modeled behavior helped patients of the experimental group to selectively attend to emotional training exercises such as pictures ,stories, and cartoon films, ignore extraneous sensory output in order to maintain adequate taskrelevant information and select appropriated actions, hence improve their emotion recognition, identification , and expression. Moreover, Positive reinforcement for the desired behavior was another related technique used throughout the training intervention in the present 
study. The researcher provided continuous reinforcement for the engagement and compliance on attending the sessions. Behavioral theories argued the importance of direct reinforcement as a way to modify or change undesirable behavior as well as increase the probability of a behavior being repeated. According to Rodewald et al (2010)., positive reinforcement was particularly relevant to the basic cognitive training, in which learning from positive reinforcement and feedback was essential for improving the emotion regulation difficulties among patients with psychiatric disorders $^{(26)}$

This result consistent with Wonet al.(2012) ${ }^{(17)}$ who stated that the experimental group who attended ERM showed a significant improvement in emotional regulation scores than those in the control group. Moreover,Mennin\&Fresco(2014) ${ }^{(27)}$ stated that interventions that focus on emotion regulation skills such as Emotion Regulation Therapy (ERT) have been shown to reduce emotional difficulties among patients with psychiatric disorders.AdditionallyCho

\&Jang (2019) ${ }^{(10)}$ stated that after attending the emotion management program, the emotion recognition and emotional expression of the experimental group were found to have significantly increased, whereas those of the control group had significantly decreased.

Social dysfunction is the deterioration of functioning in one or more basic domains, such as: interpersonal relationships, employment, or self-care. It was noticed in inability to fulfill societal defined roles such asworker,student,and spouse,also inability to care for themselves including their leisure and recreational activities. According to the diagnostic-classification system (DSM-5) it is a criterion for all psychiatric disorders including schizophrenia, mood disorders, and anxiety disorders. Kimhy et al. (2012) ${ }^{(28)}$ stated that successful social functioning requires adaptive forms of emotion regulation.Also Fett et al., (2011) ${ }^{(29)}$ emphasize the crucial role of emotion awareness impairment in determining social functioning in individuals with schizophrenia. Moreover, a study by Kimhy et al. (2016) $)^{(16)}$ stated that patients showed considerable difficulties in emotion awarenessandregulation describing feelings contribute significantly to poor SF.

It was noted that,there was a highly statistically significant improvement in social functioning in the experimental group than control group immediately after the implementation of the intervention. This is may be explained by the effect the 
intervention as it is not only facilitating the patient's emotional process regarding interpretation and regulation of their own emotion but also emotion interpretation for others which had a positive effect of interpersonal relationships.For example (exercise $3 \& 4$ ) allows patients when they are involved in a relationship, they should understand others' implied emotions through their facial expressions. Irani et al. (2012) $)^{(30)}$ found that teaching patients to recognize other's emotions is successful in solving everyday social problems and developing social interactional skills.

From another perspective, Negative emotion such as anger expression modes are important aspects on social relationship. Prolonged state of anger hinders not only the individual's mental and physical health but also histher work performance and interpersonal relationship ${ }^{(31)}$. Park et al. (2011) ${ }^{(32)}$ stated that people who used the anger-control mode had little interpersonal problems. This was the focus of emotion regulation training intervention in session (10) teaching the patients how to cope with negative emotion such as anger, anxiety, and depression.

Moreover, the intervention focused also on improving patient's emotional selfawareness. Awareness of one's emotion is essential in every social interaction because a substantial amount of information about one's emotion, attitude, status, and acceptance in social interactive situations is expressed and communicated to others through facial expressions ${ }^{(33)}$.In the same lineQu et al.(2017) ${ }^{(34)}$ stated that the awareness of one's emotion allows better understanding, prediction, and regulation of his/her states to adjust to different social interactions..

In parallel a study by Won et al. (2012) ${ }^{(17)}$ found that experimental group attended emotion management training intervention showed a significant improvement in emotional behavior, interpersonalrelationships, and social behavior than those in control group. Similar findings were reported byKimhy et al. (2012) ${ }^{(28)}$ stated that better social functioning was associated with the ability to identify, and in particular to describe emotions, and better emotion management. Moreover Javed\& Charles(2018) ${ }^{(35)}$ found that emotion management programmes enhance emotional expression, personal relations, and social behaviours in patients with schizophrenia.Recently Favrod et al.(2019) ${ }^{(36)}$ found that participation in The Positive Emotions Program for Schizophrenia (PEPS) is accompanied by an improvement of social functioning. The present study provides an evidence for the hypothesisdeclaredby Gratz et al. (2015) $^{(37)}$ that enhancing emotion 
regulation skills might be not only a promising target in the treatment of many psychiatricdisorders but also a significant factor encouraging change in various evidence-based treatments.

\section{Conclusion}

Emotion regulation training intervention had a positive effect on social functioning of patients with psychiatric disorders.

\section{Recommendation}

This study recommended that

- This non-pharmacological evidencebased-nursing practice should be incorporated in the psychiatric hospital protocol for cumulative and consistent effects.

- Provide family members or patient's caregiver with an educational program about how to deal with negative emotions and use effective emotion regulation strategies

\section{Conflictofinterest}

None declared.

\section{References}

1. Barrett L.Solving the Emotion Paradox:Categorization and the Experience of Emotion (PDF) 2017. Available:Pdfs.semanticscholar.org.

2. Meyer T, Smeets T, Giesbrecht T,Merckelbach $H$. The efficiency of reappraisal and expressive suppression in regulating everyday affective experiences. Psychiatry Research.2012; 200(23): 964-969.

3. Gross J ,Jazaieri H. Emotion, emotion regulation, and psychopathology: An affective science perspective. Clinical Psychological Science. 2014; 2(4): 387.DOI: $10.1177 / 2167702614536164$

4. Gross J. Emotion regulation: Affective, cognitive, and social consequences. Society for Psycho Physiological Research .2003; 39(3):281-291.DOI:10.1017/s00485772 01393198

5. AldaoA, SheppesG, Gross J. Emotion regulation flexibility.Cognitive Therapy Research. 2015;39(3):263-728. DOI: 10.1007/s10608-014-9662-4

6. English T, John O, Srivastava S, Gross J. Emotion Regulation and Peer-Rated Social Functioning: A four-year Longitudinal Study. Journal of Research in Personality . 2012 ;46(6):780784.DOI:10.1016/j.jrp.2012.09.006

7. Koole S. The psychology of emotion regulation: An integrative reviewcognition and emotion. Psychology Press. 2009; 23(1):4-41.

8. Arndt J\& Fujiwara E.Interactions between emotion regulation and mental health. Austin Journal of Psychiatry and Behavioural Science.2014;1(5):1-8.

9. Kring A\&Elis O.Emotion deficits in people with schizophrenia. Annual 
Review of Clinical Psychology.2013; 9(1):409-433 DOI: 10.1146/annurevclinpsy-050212-185538

10. Cho M\&Jang S.Effect of an emotion management programme for patients with schizophrenia: A quasi experimental design. International Journal of Mental Health Nursing.2019; 28(3):592-604 DOI:https://doi.org/10.1111/inm.12565

11. Green M,Bearden C, Cannon T,Fiske A,Hellemann G, Horan W.Social cognition in schizophrenia, part1:Performance across phase of illness.Schizophrenia Bulletin.2012; 38(1):854-864.

DOI:10.1093/schbul/sbq171

12. Samme C,Martino D, Strejilevich S.An individual task meta-analysis of social cognition in euthymic bipolar disorder.Journal of Affective Disorder.2015;173(1):146-153.

13. Oorschot $\mathrm{M}$,Lataster $\mathrm{T}$, Thewissen V.Emotional experience in negative symptoms of schizophrenia-no evidence for a generalized hedonic deficit. Schizophrenia Bulltein.2013; 39(1):217-

225.DOI:10.1093/schbul/sbr137

14. Gross J.Emotion regulation:Current status and future prospects.Psychological Inquiry. 2015; 26(1):1-26. Available at
https://doi.org/10.1080/1047840X.201 4.940781

15. Lin A,Wood S, Yung A. Measuring psychosocial outcome is good.Current Opinions in Psychiatry.2013; 26(2):138-43.DOI:

$$
\text { 10.1097/yco.0b013e32835d82aa }
$$

16. KimhyD,Gill K,BrucatoG.The impact of emotion awareness and regulation on social functioning in individuals at clinical high risk for psychosis.Psychological

Medicine.2016; 46(14):2907-2918. DOI: $10.1017 / \mathrm{S} 0033291716000490$

17. WonM,LeeK,LeeJ,Choi Y.Effects of an emotion management nursing program for patients with schizophrenia.Archives of Psychiatric Nursing.2012; 26(1):54-62 DOI:10.1016/j.apnu.2011.02.006

18. GratzK\&RoemerL. Multidimensional assessment of emotion regulation and dysregulation: Development, factor structure, and initial validation of the Difficulties in Emotion Regulation Scale.Journal of Psychopathology and Behavioral Assessment.2004; 26(1):41-54. DOI: $10.1007 / \mathrm{s} 10862-$ 008-9102-4

19. Birchwood M, Smith J, Coherence R,Wetton S, Copestake S.The Social Functioning Scale.The development 
and validation of a new scale of social adjustment for use in family intervention programmes with schizophrenic patients.British Journal of Psychiatry.1991;157(6):853-9 DOI: 10.1192/bjp.157.6.853

20. Hodel B\&Buenner $H$. A new development in integrated psychological therapy for schizophrenic patients (IPT): First result of emotional management training. In Brenner $\mathrm{H}$, Boker $\mathrm{W}$, GennerR. (Eds.). Toward a comprehensive therapy for schizophrenia. Toronto:Hogrefe\& Huber; 1997.118-34.

21. Taylor S F,Kang J, Brege I S,Tso I F,HosanagarA,Johnson T D.Metaanalysis of functional neuroimaging studies of emotion perception and experience in schizophrenia. Biol Psychiatry.2012; 71(2):136-45. DOI: 10.1016/j.biopsych.2011.09.007

22. BalconiM ,Cotelli M,Rossi R ,Rillosi $\mathrm{L}$,Tura $\mathrm{G}$ B.Emotion regulation in schizophrenia: A comparison between implicit and explicit (valence) measures: Preliminary observations. AsianJ.Psychiatr.2018; 34(1):12-13. DOI: 10.1016/j.ajp.2018.03.018. Epub 2018 Mar 13

23. Horan W P, Green M F, DeGroot M ,Fiske A ,Hellemann G, Kee K.Social cognition in schizophrenia, part 2:12month stability and prediction of functional outcome in first-episode patients.Schizophrenia Bulletin.2011; 38(4):865-72.DOI:10.1093/schbul/ sbr001

24. Stephanou K ,Davey C ,Kerestes R, Whittle S, Harrison B .Hard to look on the bright side:Nueral correlates of impaired emotion regulation in depressed youth. Social Cognitive and Affective Neuroscience.2017;12(7): 1138-48. DOI: 10.1093/scan/nsx039

25. Sloan E ,Hall K ,Moulding R ,Bryce S ,Mildred H, StaigerP .Emotion regulation as a transdiagnostic treatment construct across anxiety, depression, substance, eating and borderline personality disorders: A systematic review. Clinical Psychology Review.2017;57:141163.Available at:https://doi.org/ 10.1016/j.cpr.2017.09.002

26. Rodewald A , Hughes C, PittsR . Development and maintenance of choice in a dynamic environment. JournaloftheExperimentalAnalysisofB ehavior. 2010;94(2):175-95.

27. Mennin D \&Fresco D .Emotion regulation therapy.In Gross J.J (Ed.).Handbook of emotion regulation. $2^{\text {nd }}$ ed.New York : Guilford Press;2014.469-490. 
28. KimhyD,Vakhrusheva J,JobsonAhmed L, Tarrier N ,Malaspina D, Gross J.Emotion awareness and regulation in individuals with schizophrenia: Implications for social functioning. Psychiatry Research.2012; 200(23):193-201.DOI: 10.1016/j.psychres.

29. Fett A ,Viechtbauer W,Dominguez M ,Penn D ,Vanos J , Krabbendam L.The relationship between neurocognition and social cognition with functional outcomes in schizophrenia: A metaanalysis. Neuroscience and Biobehavioral Reviews.2011; 35(3):573-588. DOI: 10.1016/j. neubiorev.2010.07.001. Epub 2010 Jul 8.

30. Irani F,Seligman $S$,Kamath V, Kohler C,Gur R.Ameta-analysis of emotion perception and functional outcomes in schizophrenia. Schizophrenia Research.2012;137(1-3): 203211.DOI.org/10.1016/j.schres.2012.01.023

31. Choi J\& Lee Y.The influence of convert narcissism, anger expression styles and empathic ability on interpersonal problems of middle school students.Korean Journal of Rehabilitation

Psychology.2014;21(1):77-95. DOI :10.1016/j.jad.2014.10.055

32. Park S, Garrison Y, Cho E, Lee D.Differences in interpersonal problems and happiness by the subgroups of anger expression styles. Korean Journal of Social and
Personality Psychology.2011; 25(3):77-92.DOI: 10.21193/kjspp.

2011.25.3.006

33. North M ,Todorov A , Osherson D.Accuracy of inferring self- and other-preferences from spontaneous facial expressions.Journal of Nonverbal Behavior.2012; 36(1):227233. DOI:org/10.1007/s10919-0120137-6

34. Qu F, Yan W ,Chen Y, Li K ,Zhang H, $\mathrm{Fu} X$. You Should Have Seen the Look on Your Face:Self-awareness of facial expressions.Frontiers in Psychology.2017; $\quad$ 8(832):18.DOI:org/10.3389/fpsyg.2017.00832

35. JavedA\&Charles A. The importance of social cognition in improving functional outcomes in schizophrenia. Frontiers in Psychiatry.2018;157(9):114. DOI: $10.3389 /$ fpsyt.2018.00157. eCollection 2018.

36. FavrodJ,Nguyen A ,Tronche N .Impact of positive emotion regulation training on negative symptoms and social functioning in schizophrenia: A field test.Frontiers in Psychiatry.2019; 10(532):1-7.DOI:

\subsection{9/fpsyt.2019.00532}

37. Gratz K,Weiss N, Tull M .Examining emotion regulation as an outcome, mechanism, or target of psychological treatments. Current Opinion in Psychology.2015; 3(1):85-90. DOI:10.1016/j.copsyc.2015.02.010 